\title{
Are predatory birds effective secondary seed dispersers?
}

\author{
MANUEL NOGALES*, VICENTE QUILIS, FÉLIX M. MEDINA, JUAN L. MORA and \\ LAURA S. TRIGO
}

\author{
Departamento de Biología Animal (Zoología), 38206 Universidad de La Laguna, Tenerife, \\ Canary Islands, Spain
}

Received 10 June 2001; accepted for publication 2 November 2001

\begin{abstract}
We have studied the unusual phenomenon of secondary seed dispersal of Lycium intricatum seeds on a small oceanic Atlantic island (Alegranza, Canarian Archipelago) in which a small frugivorous lizard (Gallotia atlantica) and two different predatory birds participate, a shrike (Lanius excubitor) and a kestrel (Falco tinnunculus). Endemic lizards that are common prey of both bird species consume Lycium fruits. Lizard remains were significantly matched with the presence of Lycium fruits in the regurgitation pellets of the two predatory birds. Seeds were found in $7.3 \%$ of the lizard droppings, $31.0 \%$ of kestrel pellets and $55.7 \%$ of shrike regurgitations. The mean number of seeds per dropping or pellet was $4.8 \pm 4$ in lizard, $20.2 \pm 34.5$ in shrike and $6.7 \pm 8.1$ in kestrel. The percentage of viable seeds showed significant differences among all four treatments, decreasing in the following direction: seeds collected directly from plants (98.0\%), shrikes (88.0\%), lizards (72.3\%), and kestrels (31.7\%). Seeds from Lycium fresh fruits and shrike pellets showed significantly higher germination rates than those from lizard droppings and kestrel pellets. While lizards and shrikes are effective seed dispersers, kestrel gut treatment decreases seed viability. Seed viability is always higher than seed germination in each of the four treatments. In this island environment, Lycium seeds are under an important random influence during the seed dispersal process. Secondary seed dispersal seems to acquire a relevant dimension in small and remote insular environments or isolated continental systems where interactions among the different elements involved are intense, all of them are abundant native residents, and they have been coexisting for a long time. (C) 2002 The Linnean Society of London, Biological Journal of the Linnean Society, 2002, 75, 345-352.
\end{abstract}

ADDITIONAL KEYWORDS: Canary Islands - Falco - Gallotia - germination - Lanius - Lycium - viability.

\section{INTRODUCTION}

Frugivores are often preyed upon by raptors. During this process, seeds contained in the gut of frugivores are passed on to the predator which may act as seed disperser (Ridley, 1930; Howe \& Smallwood, 1982; van der Pijl, 1982). However, few papers have been published on this poorly understood matter (Damstra, 1986; Hall, 1987; Dean \& Milton, 1988) and the majority of them have reported descriptive information and results were not interpreted in the ecological context. A similar and more known ecological phenomenon is the secondary seed dispersal by animals, in which seeds found in vertebrate droppings are redistributed through the activity of hoarding animals (often ants),

*Corresponding author. E-mail: mnogales@ull.es and where a redistribution of seeds is carried out after the first movement of the propagules (Levey \& Byrne, 1993; Böhning-Gaese et al., 1999).

Secondary seed dispersal may be favoured if it increases one or several components of seed dispersal 'effectiveness' (Schupp, 1993). These components include the number of seeds dispersed and seed viability, among others. However, the effectiveness of secondary seed dispersal has been rarely evaluated by examining several factors simultaneously. This is particularly true for secondary seed dispersal systems mediated through frugivore-predator interactions.

Some studies have been carried out on comparisons of germination with and without ingestion by dispersers (e.g. Lieberman \& Lieberman, 1986; Barnea et al., 1990, 1991; Izhaki \& Safriel, 1990). Some general patterns have been observed and results obtained depending on the species involved in each 
interaction (see review of Traveset \& Verdú, 2002). Other contributions have addressed the effects of different vertebrate groups of dispersers on germination of particular plant species, sometimes finding significant differences between the dispersal agents (Mandujano et al., 1994; Traveset et al., 2001) but not always (Lieberman \& Lieberman, 1986; Traveset \& Willson, 1997). Despite the interest in the secondary seed dispersal system by vertebrates preying upon frugivores, at the moment few contributions have studied the effect that birds can produce on the germination of seeds dispersed secondarily (Balgooyen \& Moz, 1973; Nogales et al., 1998).

Oceanic Islands, often represented by simple habitats, harbour ideal systems in which to study complex ecological interactions. Some studies have mentioned the important role of reptiles as seed dispersers on islands worldwide (Rick \& Bowman, 1961; Iverson, 1985; Whitaker, 1987; Valido \& Nogales, 1994; Traveset, 1995). To address the question of how birds affect the germination of seeds dispersed secondarily, we will focus on a unique system found in Alegranza Islet, a small island located in the north-east of the Canarian Archipelago (near Lanzarote Island), which is made up of a simple system where it is possible to study the effect of two different predatory birds, a shrike Lanius excubitor L. (O. Passeriformes) and a kestrel Falco tinnunculus L. (O. Falconiformes) as secondary seed dispersers of Lycium intricatum Boiss (Solanaceae) fruits. Both species of birds prey intensively upon the frugivorous lizard Gallotia atlantica Peters and Doria (Lacertidae) on Alegranza, where L. intricatum is practically the only fleshy-fruit plant species growing.

Gut enzymatic action is very variable depending on the type of predatory bird, being much stronger in the case of diurnal birds of prey compared with other non-specialized predatory birds (Brown et al., 1993; Stuart \& Stuart, 1994). This strong raptor stomach acidity can mineralize bones and therefore may affect germination through its influence on chemical or mechanical abrasion of the Lycium seed coat. Because diurnal birds of prey, such as the kestrels, have stronger enzymatic action and longer regurgitation time than the shrikes (see Balgooyen, 1971; Duke et al., 1976; Yalden \& Yalden, 1985; Olsson, 1984, 1985), and because of the apparent relative thickness of the seed coat of Lycium seeds, we expected that the kestrel would negatively affect viability and germination rates compared to shrikes. However, the contrary seed effect seems to occur with the gut treatment of the shrikes which function as effective seed dispersers, according to germination data obtained by Nogales et al. (1998).

The four main objectives of the present study were: (1) to confirm whether the presence of lizard prey remains and Lycium seeds both in shrike and kestrel pellets reveal these predators as secondary seed dispersers (2) to assess the relative importance of lizards, shrikes, and kestrels in the primary and secondary dispersal of Lycium seeds (3) to evaluate the damage to the seeds eaten by all disperser agents and the viability after passing several gut treatments, and (4) to check for possible differences in germination rates of Lycium seeds exposed to the different dispersal treatments (directly collected from plants, lizard droppings, shrike and kestrel pellets). This is the first study we are aware of on secondary seed dispersal by vertebrates preying upon frugivores where viability and germination for all treatments of a dispersal system is systematically studied.

\section{METHODS}

\section{STUdy Site}

The Canarian Archipelago is of volcanic origin and lies in the Atlantic Ocean about $100 \mathrm{~km}$ (at the nearest point) from the African continent. Alegranza is uninhabited and is the Northernmost island of the Canaries, being situated about $17 \mathrm{~km}$ from the north coast of Lanzarote. It comprises $10.5 \mathrm{~km}^{2}$ with elevations ranging from 0 to 289 ma.s.l. The climate is semidesertic; mean annual temperature is around $21^{\circ} \mathrm{C}$ and total annual rainfall does not exceed $300 \mathrm{~mm}$. The vegetation is sparse and dominated by xeric shrubs including Chenoleoides tomentosa (Lowe) Botshand, Salsola vermiculata L. (Chenopodiaeae), Euphorbia obtusifolia Poir. (Euphorbiaceae), Lycium intricatum and Nicotiana glauca Grah. (Solanaceae). For more information on Alegranza Islet and part of the system studied, see Martín \& Nogales (1993) and Nogales et al. (1998), respectively.

\section{PRocedures}

Fieldwork was carried out during the springs of 1997 (28 April to 1 May) and 1998 (27 April to 1 May). We conducted extensive surveys of the island in search of Lycium fruits $(N=314)$ from 70 different plants, droppings of lizards $(N=993)$, and of shrikes $(N=106)$ and kestrel pellets $(N=210)$. In order to have a representative sample of the population involved in the process, we collected lizard droppings in at least 28 distant places, and shrike and kestrel pellets in 15 and three different and distant perches, respectively. Lizards (SVL: $61-95 \mathrm{~mm} ; N=20$ ) are very abundant in Alegranza while shrike and kestrel breeding populations have been estimated in five and four pairs, respectively (data from 1998).

Seeds were manually extracted and counted from the different lizard droppings and predatory birds pellets individually. Seeds recovered from fruits and 
from the three vertebrate species were examined for their viability and ability to germinate. We performed a comparison viability experiment using $2,3,5$ triphenyl tetrazolium (TTC) test (Scharpf, 1970) on seeds, collected in spring 1998, from the four treatments ( $N=199$ seeds collected directly from plants or uningested, 191 from lizard droppings, 200 from shrike pellets and 187 from kestrel pellets). Seeds were previously immersed in water during $24 \mathrm{~h}$ before being included in TTC and kept in the dark during the same time period. Additionally, we ran a germination experiment in a greenhouse, including seeds from spring 1997, of the same four seed treatments $(N=104$ seeds, from each). Every seed was planted in an individual pot and we used a standard substrate (lapilli, turf and forest soil in a ratio of 1-1-2); the experience was examined daily for three months until no germination was found. Seeds were watered every two days and night-day light period conditions were those naturally found in the study area. Germination was defined as the emergence of any seedling part from the soil surface.

To test whether seeds of Lycium in the two predators occurred in association with lizard bones, we recorded their presence in each pellet individually and we used Chi-square tests to assess such association. This analysis was also used to identify possible differences in viability and germination from seeds belonging to the four treatments. We used a Kolmogorov-Smirnov test to study the germination speed among different seed types. All analyses were performed by using SPSS (version 9.0).

\section{RESULTS}

\section{PLANT AND SEED DISPERSAL SYSTEM}

Lycium intricatum is a common thorny solanaceous shrub that can reach $2 \mathrm{~m}$ in height in the xerophytic coastal Canarian areas. Fruits ripen in winter/spring, turn red (measure: $7.75 \pm 1 \mathrm{~mm}$ in length; mean \pm 1 $\mathrm{SD}, 5.17 \pm 2 \mathrm{~mm}$ in diameter, $0.12 \pm 0.1 \mathrm{~g}$ in fresh weight, a water content of $71.72 \pm 7 \%$; seed length is $\approx 2 \mathrm{~mm}$; number of seeds present in fresh fruits range between 1 and 17, mean $=7.43 \pm 3 ; N=40$ fruits).

Lycium seeds were found in $7.3 \%$ of the lizard droppings analysed (993 in total) and mean number of seeds per droppings was $4.8 \pm 4$ (range $=1-22$ ). Frequency of occurrence of lizard remains was found to be the same for shrike and kestrel pellets $(74 \%)$. The two predatory bird species are secondary dispersers of Lycium seeds according to the high association found between seeds and lizard remains in the pellets of both species (Table 1). This association was consistent between the two years and in $49.1 \%$ of shrike pellets and $31.0 \%$ from kestrel pellets were matched (Table 1). Frequency of seed occurrence and mean number of seeds per pellet was higher in shrike than in kestrel ones (Table 2).

\section{SEED VIABILITY AND GERMINATION}

The external visual damage produced by lizards to Lycium seeds was very small and a similar effect was observed in the case of the regurgitated seeds from the two predatory birds after a second treatment (Table 2). Highly significant differences were observed in seed viability among all combinations of the four treatments, decreasing in the following direction: uningested seeds, shrikes, lizards, and kestrels (Fig. 1 and Table 3).

A total of 233 seeds (56.0\%) germinated of the 416 seeds planted (Fig. 1). Seeds from kestrel pellets suffered a reduction in germination of one third relative to those obtained from lizard droppings and of about one fourth relative to shrike seeds and uningested Lycium seeds. Furthermore, a smaller reduction of the seeds taken from lizard droppings with regards to those from shrike regurgitations and

Table 1. Results of Chi-square tests for association of Lycium intricatum seeds and Gallotia atlantica remains in regurgitation pellets from Lanius excubitor and Falco tinnunculus on Alegranza

\begin{tabular}{|c|c|c|c|c|c|c|}
\hline \multirow[b]{2}{*}{ Items } & \multicolumn{3}{|l|}{ Lanius } & \multicolumn{3}{|l|}{ Falco } \\
\hline & 1997 & 1998 & Pooled & 1997 & 1998 & Pooled \\
\hline Lycium and lizard & 16 & 36 & 52 & 19 & 46 & 65 \\
\hline Lycium alone & 2 & 5 & 7 & 0 & 0 & 0 \\
\hline Lizard alone & 11 & 9 & 20 & 25 & 66 & 91 \\
\hline None & 17 & 10 & 27 & 28 & 26 & 54 \\
\hline Total pellets & 46 & 60 & 106 & 72 & 138 & 210 \\
\hline$\chi_{1}^{2}$ & 9.2 & 9.2 & 22.9 & 14.3 & 14.2 & 30.6 \\
\hline$P$ & 0.002 & 0.001 & $<0.0001$ & $<0.0001$ & $<0.0001$ & $<0.0001$ \\
\hline
\end{tabular}


Table 2. Lycium intricatum seeds found in the droppings of Gallotia atlantica and the pellets of Lanius excubitor and Falco tinnunculus on Alegranza

\begin{tabular}{lccc}
\hline Parameters & Gallotia & Lanius & Falco \\
\hline Number of droppings/pellets studied & 993 & 106 & 210 \\
Droppings/pellets with seeds (\%) & 7.3 & 55.7 & 31.0 \\
Number of seeds per droppings/pellets (mean \pm SD) & $4.8 \pm 4$ & $20.2 \pm 34.5$ & $6.7 \pm 8.1$ \\
Range of seeds per droppings/pellets & $1-22$ & $1-134$ & $1-39$ \\
Total number of seeds found & 331 & 1202 & 389 \\
Damaged seeds (visual inspection \%) & 3.0 & 1.2 & 1.3 \\
\hline
\end{tabular}

Table 3. Statistical results obtained from the viability tests $(2,3,5$ triphenyl tetrazolium) and germination experiments of Lycium intricatum seeds based on the four seed treatments on Alegranza

\begin{tabular}{|c|c|c|c|c|c|c|}
\hline \multirow[b]{2}{*}{ Seed treatment } & \multicolumn{3}{|c|}{ Viability } & \multicolumn{3}{|c|}{ Germination } \\
\hline & $\chi^{2}$ & d.f. & $P$ & $\chi^{2}$ & d.f. & $P$ \\
\hline Lycium vs. Gallotia & 49.69 & 1 & $<0.0001^{*}$ & 8.61 & 1 & $0.003^{*}$ \\
\hline Lycium vs. Lanius & 13.76 & 1 & $<0.0001^{*}$ & 0.40 & 1 & 0.527 \\
\hline Lycium vs. Falco & 220.89 & 1 & $<0.0001^{*}$ & 67.09 & 1 & $<0.0001^{*}$ \\
\hline Gallotia vs. Lanius & 14.34 & 1 & $<0.0001^{*}$ & 5.37 & 1 & 0.020 \\
\hline Gallotia vs. Falco & 85.93 & 1 & $<0.0001^{*}$ & 31.04 & 1 & $<0.0001^{*}$ \\
\hline Lanius vs. Falco & 158.67 & 1 & $<0.0001^{*}$ & 58.61 & 1 & $<0.0001^{*}$ \\
\hline
\end{tabular}

* Significant at Bonferroni-corrected $P$ level $(0.05 / 6=0.008)$.

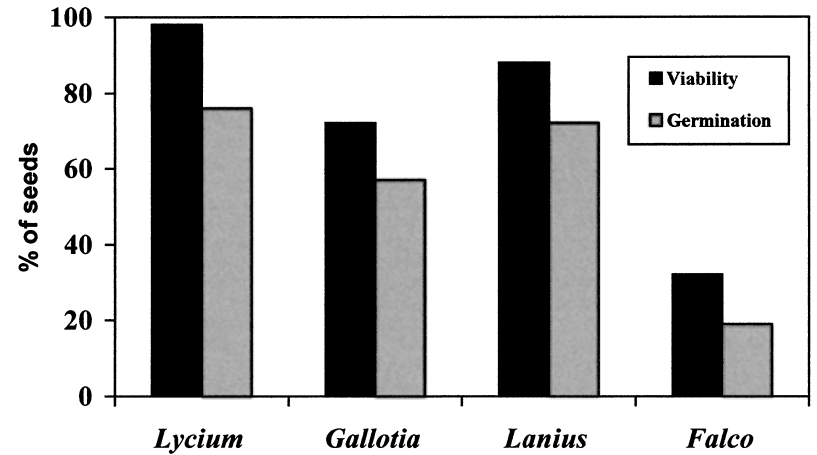

Figure 1. Viability and germination observed in the Lycium intricatum seeds from the four treatments (fresh fruits, droppings of Gallotia atlantica, and regurgitation pellets of Lanius excubitor and Falco tinnunculus) on Alegranza.

Lycium fruits was observed (Table 3), being only statistically significant with respect to the latter. There were no significant differences between seeds of these two last treatments.

Seeds from Lycium fruits germinated significantly earlier than those from the other three treatments
(Kolmogorov-Smirnov tests, $P<0.0001$ ) (Fig. 2). Seeds from shrike pellets emerged sooner than those from lizard droppings $(Z=4.47, P<0.0001)$ and kestrel pellets $(Z=4.83, P<0.0001)$. Seeds from lizard droppings germinated earlier than seeds from kestrel pellets $(Z=4.74, P<0.0001)$. These results were also significant at Bonferroni-corrected $P$ level $(0.05 / 3=0.016)$.

\section{DISCUSSION}

\section{RELATIVE IMPORTANCE OF EACH DISPERSER}

Secondary seed dispersal is a very little know phenomenon in which mainly birds (Ridley, 1930; Damstra, 1986; Hall, 1987; Dean \& Milton, 1988; Stiles, 1992; Nogales et al., 1998) and mammals (Nogales et al., 1996) participate as secondary dispersers. The majority of cases described in the process of secondary seed dispersal by vertebrates involve frugivorous passerine birds as primary dispersers. In the present system, a frugivorous lizard achieves the first step. Our results show that shrikes and kestrels act as potential secondary seed dispersers due to the high association found between Lycium seeds and lizard remains in their pellets. Furthermore, lizards are 

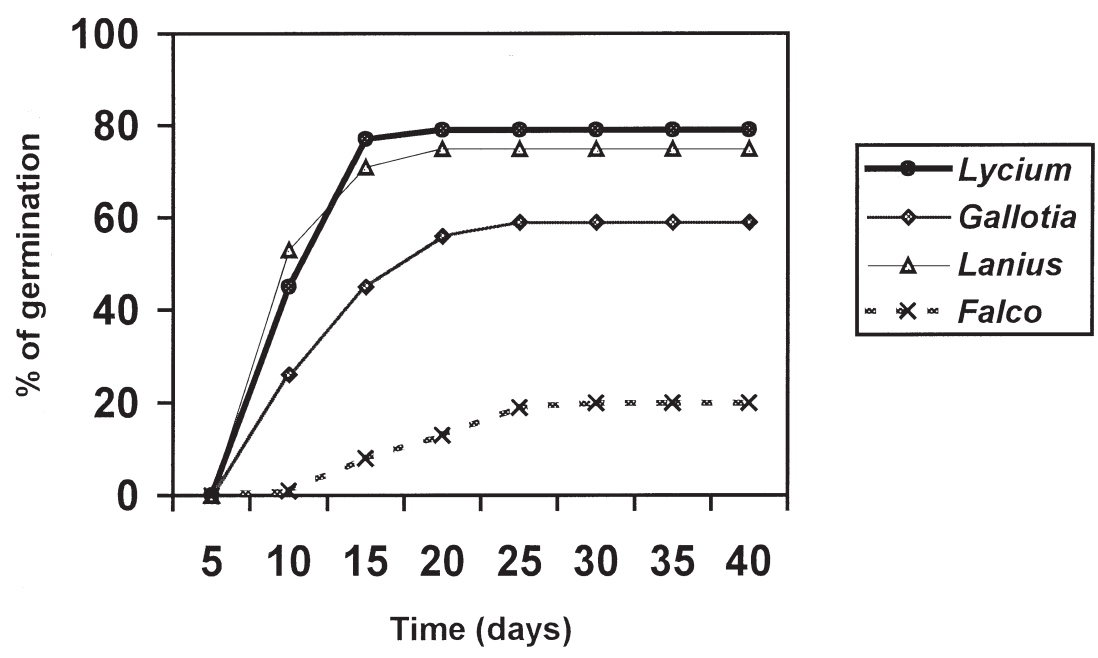

Figure 2. Seed germination rates from Lycium intricatum obtained from fresh fruits, droppings of Gallotia atlantica, and regurgitation pellets of Lanius excubitor and Falco tinnunculus on Alegranza.

common prey in the diet of shrikes and kestrels on Alegranza (Nogales et al., 1998; M. N. Zurita \& N. Puerta, unpub. data), reaching $18.1 \%$ and $13.5 \%$ of the total prey consumed and representing a total biomass of $64.3 \%$ and $50 \%$, respectively (T. Barrera \& R. González, unpubl. data).

In order to assess the efficiency of the three different vertebrates involved in this particular system, one of the most important factors in seed dispersal is the number of seeds transported by each dispersal agent (Schupp, 1993). In this system, frequency of apparition of Lycium seeds was approximately four times greater in the pellets of both predatory bird species than in lizard droppings (Table 2). Furthermore, lizards and kestrels have a similar mean number of seeds per dropping (4.8 and 6.7, respectively) whereas shrike pellets have four-fold more. Although defecation and regurgitation rates range between one and two droppings per day for the three disperser species (Duke et al., 1976; Olsson, 1984, 1985; A. Valido \& M. Nogales, unpubl. data), a higher number of seeds is probably transported by lizards due to their great abundance in the islet.

\section{SEED DEPOSITION}

Seed deposition, referred to as the mean number of seeds per dropping, seems to be very different when comparing lizard and kestrel droppings with shrike pellets, being clearly higher in the latter (see Table 2). If we consider that seed clumping has important and negative implications for seed survival, germination and seedling competition (Jordano, 1992), these results suggest that lizards and kestrels are more beneficial as dispersers than shrikes in this particular aspect of the dispersal system. However, the two predatory birds produce a more seed clumped spatial distribution than lizards since they frequently use perches. In any case, the combination of both primary and secondary seed dispersers in this system results in a more heterogeneous seed shadow than that expected if interactions were only with lizards.

\section{DISPERSER EFFECTIVENESS AND SEED GERMINATION}

The viability tests performed in our study indicate that while lizards and shrikes (direct and secondary, respectively) do not affect the viability and germination of the Lycium seeds negatively, kestrels clearly do. These results are consistent with those showing that many vertebrate frugivorous species do not affect seed viability when they ingest seeds (Stiles, 1992; Traveset, 1998). Despite the utility of the viability test in seed germination studies, few contributions have examined seed viability before performing germination (Holthuijzen \& Sharik, 1985; Nogales et al., 1999).

With regards to secondary seed dispersal systems previously described, Hall (1987) observed that the majority of seeds secondarily ingested by raptors were apparently unharmed. Furthermore, the capacity of germination of seeds of the grass Calamagrostis canadensis (Michx.) Beauv. after suffering a double digestion of a frugivorous passerine and an American Kestrel (Falco sparverius L.) has been anecdotically mentioned by Balgooyen \& Moz (1973).

In general, two of the main factors that affect seed germination are retention time in the gut of each species (e.g. Levey, 1986; Barnea et al., 1992) and treatment effects in the digestive tract of every disperser (Schupp, 1993). Furthermore, it is known that 
seed regurgitation time by frugivorous birds is short (5-20 min), while seeds that are defecated spend a longer period being digested, usually in the range 20-90 min (Levey, 1986; Snow \& Snow, 1988; Jordano, 1992). Seeds that have been voided rapidly seem more likely to germinate than those that have been under a long gut retention time (e.g. Murray et al., 1994). In our system, species involved show very different gut passage time (GPT) in lizards and regurgitation time (RT) in predatory birds. Lizard GPT was measured in laboratory conditions ( $12 \mathrm{~h}$ daylight, $26-28^{\circ} \mathrm{C}, N=20$ individuals) by giving a glass bead, similar in size to a Lycium seed, and it yielded an average time of 2.4 days (A. Valido \& M. Nogales, unpubl. data). In contrast, shrike RT is rather short (45-55 min; Olsson, 1984, 1985). For kestrels, Balgooyen (1971), Duke et al. (1976) and Yalden \& Yalden (1985) observed a period of $12-23.5 \mathrm{~h}$.

Gut enzymatic action of diurnal raptors is clearly stronger than in other types of birds (Duke et al., 1976; Brown et al., 1993; Stuart \& Stuart, 1994). In our case it seems clear that the gut effect on secondarily ingested seeds is lower for shrike pellets than for kestrels. However, despite the fact that lizards showed a GPT wich was about twice the Kestrel RT, this raptor reduced seed viability and germination rate to about one third. In this respect, it is also interesting to note that seed retention time, and therefore lizard gut treatment, is shorter when a bird predates a lizard (Nogales et al., 1998). This fact has an important implication in seed germination (Fig. 1), and Nogales et al. (1998) found similar results for germination pattern and percentages on part of the system presented here (plant-lizard-shrike).

Viability rates are higher than germination rates in all four Lycium seed treatments in this study (Fig. 1), so they could be influenced by an inhibitory process that reduces germination. Inhibitory effects in germination have been recorded by several authors in some species from temperate habitats (e.g. Livingston, 1972; Smith, 1975). Germination may be inhibited by several causes: anaerobic atmospheres, extreme temperatures, dry conditions, different acid types, among others (Murdoch \& Ellis, 1992). Nevertheless, mechanisms underlying promotion and inhibition by chemical factors are largely unknown (Karssen \& Hilhorst, 1992).

The fact that primary and secondary dispersal agents alter the speed of germination (Fig. 2) is difficult to interpret although it could have ecological implications as in the length of exposure to postdispersal seed predators, the finding in ephemeral seedling microsites (Schupp, 1993) or advantages in seedling size (Traveset et al., 2001). Furthermore, early germination might be related to arid ecosystems where rain is unpredictable (Izhaki \& Safriel, 1990).
In the xeric islet of Alegranza, we observed significant differences among the four treatments, in order of emergence: seeds from shrikes, Lycium fresh fruits, lizards and kestrels.

\section{GENERAL ECOLOGICAL CONSIDERATIONS}

As mentioned in the introduction, secondary seed dispersal by vertebrates preying upon frugivores shows relative analogies with the secondary seed dispersal in which seeds found in vertebrate droppings are redistributed though the activity of hoarding animals (e.g. ants; Levey \& Byrne, 1993; BöhningGaese et al., 1999). However, secondary seed dispersal by vertebrates includes a second digestion of seeds which does not occur in the hoading process. Furthermore, secondary seed dispersal by hoarding animals modifies seed shadow less intensively because the second movement is performed on a smaller spatial scale. In the case of the secondary seed dispersal by predatory birds, the seeds are clearly dispersed at larger distances as a consequence of the second seed movement. In this respect, and on a larger spatial scale, Moore (1999) mentioned that movement of seeds from lizards to birds increases the opportunities for island-dwelling plants, giving them a greater chance of moving to new islands. Although this process might occur rarely and it would be very difficult to demonstrate, this author has considered that like other events in island biology, given enough time it can probably come about.

On our insular environment scale, Lycium seeds are under an important random component during the seed dispersal process. Dissemination can be done directly by a lizard, or secondarily by a shrike or a kestrel providing different ecological advantages (under the legitimacy view) depending on the disperser type. In general, this complex dispersal system can be considered advantageous for L. intricatum, considering the wide distribution that this species enjoys in all the Canary Islands and islets, and its abundance in all the lowland habitats of the Archipelago.

Finally, despite being poorly known, secondary seed dispersal by predatory birds may acquire an important dimension in small and remote insular environments or isolated continental systems where interactions are quite intense; all the participants are abundant, native residents, which have been interacting for a long time.

\section{ACKNOWLEDGEMENTS}

We thank A. Valido for supplying data on fruit traits and who read an earlier version of the manuscript. 
F. Valdés gave technical assistance on performing seed viability tests and P. Jordano, D. Wenny, P. Moore, A. Traveset, J. Alonso and C. Nieves provided all kinds of advice. We specially thank the Armada Española (Zona Marítima de Canarias) for transporting the researchers and the equipment to Alegranza.

\section{REFERENCES}

Balgooyen TG. 1971. Pellet regurgitation by captive Sparrow Hawks (Falco sparverius). Condor 73: 382-385.

Balgooyen TG, Moz T. 1973. Dispersal of grass-fruits - an example of endornithochory. American Midland Naturalist 90: $454-455$.

Barnea A, Yom-Tov Y, Friedman J. 1990. Differential germination of two closely related species of Solanum in response to bird ingestion. Oikos 57: 222-228.

Barnea A, Yom-Tov Y, Friedman J. 1991. Does ingestion by birds affect seed germination? Functional Ecology 5: 394-402.

Barnea A, Yom-Tov Y, Friedman J. 1992. Effect of frugivorous birds on seed dispersal and germination of multi-seeded fruits. Acta Oecologica 13: 209-219.

Böhning-Gaese K, Gaese BH, Rabemanantsoa SB. 1999. Importance of primary and secondary seed dispersal in the Malagasy tree Commiphora guillaumini. Ecology 80: 821-832.

Brown RW, Lawrence MJ, Pope J. 1993. Animals tracks, trails and signs. London: Hamlyn Publishing Group Limited.

Damstra K. 1986. Editorial (notes by George Hall). Tree Life 71: 5 .

Dean WRJ, Milton SJ. 1988. Dispersal of seeds by raptors. African Journal of Ecology 26: 173-176.

Duke GE, Evanson OA, Jegers A. 1976. Meal to pellet intervals in 14 species of captive raptors. Comparative Biochemical Physiology 53A: 1-6.

Hall G. 1987. Seed dispersal by birds of prey. Zimbabwe Science News 21: 1-2.

Holthuijzen AMA, Sharik TL. 1985. The avian seed dispersal system of eastern red cedar (Juniperus virginiana). Canadian Journal of Botany 63: 1508-1515.

Howe HF, Smallwood J. 1982. Ecology of seed dispersal. Annual Review of Ecology and Systematics 13: 201-228.

Iverson JB. 1985. Lizards as seed dispersers?. Journal of Herpetology 19: 292-293.

Izhaki I, Safriel UN. 1990. The effect of some Mediterranean scrubland frugivores upon germination patterns. Journal of Ecology 78: 56-65.

Jordano P. 1992. Fruits and frugivory. In: Fenner M, ed. Seeds: the ecology of regeneration in plant communities. Wallingford, Oxon: CAB International, 105-156.

Karssen CM, Hilhorst HWM. 1992. Effect of chemical environment on seed germination. In: Fenner M, ed. Seeds: the ecology of regeneration in plant communities. Wallingford, Oxon: CAB International, 327-348.

Levey DJ. 1986. Methods of seed processing by birds and seed deposition patterns. In: Estrada A, Flemming TH, eds. Frugivores and seed dispersal. Dordrecht: Junk, 147-158.
Levey DJ, Byrne MM. 1993. Complex ant-plant interactions: rain forest ants as secondary dispersers and post-dispersal seed predators. Ecology 74: 1802-1812.

Lieberman M, Lieberman D. 1986. An experimental study of seed ingestion and germination in a plan-animal assemblage in Ghana. Journal of Tropical Ecology 2: 113-126.

Livingston RB. 1972. Influence of birds, stones and soil on the establishment of pasture juniper, Juniperus communis, and red cedar, J. virginiana in New England pastures. Ecology 53: 1141-1147.

Mandujano S, Gallina S, Bullock SH. 1994. Frugivory and dispersal of Spondias purpurea (Anacardiaceae) in a tropical deciduous forest in Mexico. Revista de Biología Tropical 42: 107-114.

Martín A, Nogales M. 1993. Ornithological importance of the Island of Alegranza (Canary Islands). Boletim do Museu Municipal do Funchal 3: 167-179.

Moore P. 1999. A shrike for mobility. Nature 397: 22-23.

Murdoch AJ, Ellis RH. 1992. Longevity, viability and dormancy. In: Fenner M, ed. Seeds: the ecology of regeneration in plant communities. Wallingford, Oxon: $\mathrm{CAB}$ International, 139-229.

Murray KG, Russell S, Picone CM, Winnett-Murray K, Sherwood W, Kuhlmann ML. 1994. Fruit laxatives and seed passage rates in frugivores: consequences for plant reproductive success. Ecology 75: 989-994.

Nogales M, Delgado JD, Medina FM. 1998. Shrikes, lizards and Lycium intricatum (Solanacea) fruits: a case of indirect seed dispersal on an oceanic island (Alegranza, Canaries). Journal of Ecology 86: 866-871.

Nogales M, Hernández EC, Valdés F. 1999. Seed dispersal by Common Ravens Corvus corax among island habitats (Canarian Archipelago). Écoscience 6: 56-61.

Nogales M, Medina FM, Valido A. 1996. Indirect seed dispersal by the feral cats Felis catus in island ecosystems (Canary Islands). Ecography 19: 3-6.

Olsson V. 1984. The winter habits of the Great Grey Shrike, Lanius excubitor. 3. Hunting methods. Var Fagelvärld 43: 405-414.

Olsson V. 1985. The winter habits of the Great Grey Shrike, Lanius excubitor. 4. Handling of prey. Var Fagelvärld 44: 269-283.

van der Pijl L. 1982. Principles of dispersal in higher plants. Berlin: Springer.

Rick CM, Bowman RI. 1961. Galapagos tomatoes and tortoises. Evolution 15: 407-417.

Ridley HN. 1930. The dispersal of plants throughout the world. Ashford: L. Reeve.

Scharpf RF. 1970. Seed viability germination and radicle growth of dwarf mistletoe in California. California: USDA Forest Service Research, Paper PSW-59.

Schupp EW. 1993. Quantity, quality and the effectiveness of seed dispersal by animals. In: Fleming TH, Estrada A, eds. Frugivory and seed dispersal: ecological and evolutionary aspects. Dordrecht: Kluwer, 15-29.

Smith AJ. 1975. Invasion and ecesis of bird-disseminated woody plants in a temperate forest sere. Ecology 56: 1434 . 
Snow B, Snow D. 1988. Birds and berries. Calton: T \& $\mathrm{AD}$ Poyser Ltd.

Stiles EW. 1992. Animal as seed dispersers. In: Fenner M, ed. Seeds: the ecology of regeneration in plant communities. Wallingford, Oxon: CAB International, 87-104.

Stuart C, Stuart T. 1994. Tracks and signs of southern and east African wildlife. Cape Town: Southern Book Publishers.

Traveset A. 1995. Seed dispersal of Cneorum tricoccon L. (Cneoraceae) by lizards and mammals in the Balearic islands. Acta Oecologica 16: 171-178.

Traveset A. 1998. Effect of seed passage through vertebrate frugivores' guts on germination: a review. Perspectives in Plant Ecology, Evolution and Systematics 1/2: 151-190.

Traveset A, Riera N, Mas RE. 2001. Passage through bird guts causes interspecific differences in seed germination characteristics. Functional Ecology 15: 669-675.
Traveset A, Verdú M. 2002. A meta-analysis of the effect of gut treatment on seed germination. In: Levey DJ, Silva WR, Galetti M, eds. Seed dispersal and frugivory: ecology, evolution and conservation. Wallingford, Oxon: CAB International, 339-350.

Traveset A, Willson MF. 1997. Effect of birds and bears on seed germination of fleshy-fruited plants in temperate rainforests of southeast Alaska. Oikos 80: 89-95.

Valido A, Nogales M. 1994. Frugivory and seed dispersal by the lizard Gallotia galloti (Lacertidae) in a xeric habitat of the Canary Islands. Oikos 70: 403-411.

Whitaker AH. 1987. The roles of lizards in New Zealand plant reproductive strategies. New Zealand Journal of Botany 25: 315-328.

Yalden DW, Yalden PE. 1985. An experimental investigation of examining Kestrel diet by pellet analysis. Bird Study 32: $50-55$. 